\title{
As Time Goes By: What Changes and What Remains the Same in Entertainment Experience Over the Life Span?
}

\author{
Anne Bartsch \\ Martin Luther University Halle \\ University of Augsburg
}

Bartsch, A. (2012). As time goes by: What changes and what remains the same in entertainment experience over the life span? Journal of Communication, 62(4), 588-608. doi: $10.1111 / \mathrm{j} .1460-2466.2012 .01657 . \mathrm{x}$

The definitive version is available at http://onlinelibrary.wiley.com/doi/10.1111/j.1460$\underline{2466.2012 .01657 . x}$

This article may not exactly replicate the final version published in the previously mentioned Journal. It is not the version of record and is therefore not suitable for citation.

Acknowledgements: The author would like to thank Reinhold Viehoff, Roland Mangold, and Peter Vorderer for their support and advice with this research.

Funding: This work was supported by the German Research Foundation [grant number Vi 95/17].

Corresponding author: anne.bartsch@phil.uni-augsburg.de 


\begin{abstract}
Across all age groups, entertainment is one of the most important motivations for media use. Relatively little is known, though, about the development of entertainment experience over the life span. Does entertainment actually mean the same thing to young and older people? Based on theories of adult emotional development, affect regulation, and wellbeing, this study predicted and found that in terms of entertainment gratifications sought, young adults were more interested than older adults in emotionally intense entertainment experiences such as thrilling and tear-jerking experiences, whereas older adults were more interested in contemplative entertainment experiences. However, in terms of gratifications obtained, ratings of film scenes showed that the same types of gratifications obtained predicted more positive evaluations independent of age.
\end{abstract}

Keywords: entertainment, age, adult development, emotion-regulation, well-being 
As Time Goes By. What Changes and What Remains the Same in Entertainment Experience Over the Life Span?

Across all age groups, entertainment has been identified as one of the most important motivations for media use (Conway \& Rubin, 1991; Mundorf \& Brownell, 1990). But what exactly does entertainment mean to young and older people? Research on age differences in content and genre preferences raises doubts about the existence of a one-fit-all entertainment formula. For example, typical content characteristics of entertainment geared toward young adults such as sex and violence tend to be offensive for older adults, whereas quiz shows, nostalgic and informational content tend to be more popular with older audiences (Mares \& Sun, 2010; van der Goot, Beentjes, \& van Selm, 2006). Further, when asked to name their favorite movies, older adults were more likely than young adults to cite dramas and musicals, and were less likely to cite horror, actionadventure, and comedy titles (Fischoff, Antonio, \& Lewis, 1998).

The varying popularity of entertainment choices among different age groups raises interesting theoretical questions about the development of underlying needs and viewing motivations. What motivates young and older adults' selection of different entertainment diets? What makes entertainment worthwhile and gratifying at different stages of life? Against the background of increasing life expectancy, and the growing amount of time that people spend with entertainment media as they grow older (van der Goot, et al., 2006), it seems important to better understand the specific appeals and functions of entertainment for this age group, and to elucidate the different ways in which entertainment can contribute to individuals' sense of gratification and well-being across the life span.

An emerging line of research (Bartsch, in press; Mares, Oliver \& Cantor, 2008; Mares \& Sun, 2010) has begun to address these questions about the development of entertainment experience over the life span by linking recent conceptualizations of eudaimonic entertainment gratification (Oliver, 2008; Oliver \& Raney, 2011) with theories of adult emotional development (Carstensen, Fung, \& Charles, 2003; Ersner-Hershfield, Mikels, Sullivan, \& Carstensen, 2008). Taken together, 
these frameworks suggest that age differences in entertainment use can be (partly) understood in terms of individuals' changing goals and strategies of emotion regulation, and their evolving sense of emotional well-being. In line with general processes in adult emotional development, it seems that older adults become less interested in emotionally intense entertainment experiences, such as thrilling and tear-jerking experiences, and that they become more interested in entertainment experiences that are heartwarming, contemplative, and socially meaningful. The present study aims to extend this line of research by providing intercultural validation, and by distinguishing between gratifications sought, and gratifications obtained from actual exposure to entertainment media.

\section{Theoretical Background and Hypotheses}

\section{Affect Regulation as a Motivation for Entertainment Use}

The capacity of entertainment media to elicit affective responses (including mood, arousal, and discrete emotions) is often considered a key motivation for entertainment use. Entertainment audiences want to have a good laugh, they want to be kept at the edge of their seats, or be moved to tears (Oliver, 1993; Zillmann, 1988; Zuckerman, 1979). This salience of affective factors has stimulated different lines of research that offer theoretical explanations why affective responses can be desirable and rewarding for media users_-including such concepts as mood management (Zillmann, 1988), sensation seeking (Zuckerman, 1979), excitation transfer (Zillmann, 1996), affective disposition (Zillman \& Cantor, 1977), meta-emotion (Oliver, 1993), social comparison (Mares \& Cantor, 1992), parasocial relationships (Rubin \& Perse, 1987), and eudaimonia (i.e., gratifications related to social and emotional meaningfulness, Oliver, 2008). For an overview see Bartsch, Vorderer, Mangold, and Viehoff (2008).

The diversity of theoretical assumptions about the role of affect as a motivation for entertainment use is also echoed in individuals' self-report. Bartsch (in press) found a set of seven factors in individuals' self-report of emotionally gratifying experiences when watching movies and TV series. Three of the factors were related to specific feelings: 1) fun, 2) thrill, and 3) empathic sadness, whereas the remaining four factors were related to the function of emotional media 
experiences within the broader context of individuals' social and cognitive needs: 4) contemplative emotional experiences, 5) emotional engagement with characters, 6) social sharing of emotions, and 7) vicarious release of emotions.

Recent conceptualizations of entertainment as an intrinsically rewarding activity (Oliver \& Bartsch, 2010; Sherry, 2004; Tamborini, Bowman, Eden, Grizzard, \& Organ, 2010; Vorderer, Steen, $\&$ Chan, 2006) have provided a handy and parsimonious formula that covers both types of affective gratifications, that is, rewarding feelings, and psychosocial functions of emotions. Through the lens of an intrinsic motivation framework (Csikszentmihalyi, 1990; Ryan \& Deci, 2000), media experiences are entertaining to the extent that the affective, cognitive and social aspects of the experience are gratifying in and of themselves, independent of extrinsic rewards — which applies to rewarding feelings as well as to the gratification derived from rewarding social and cognitive processes that can be stimulated by emotional media experiences (such as parasocial relationships, reflectiveness, or conversations with others).

Taken together, the theoretical and empirical evidence suggests that entertainment media can serve different functions in terms of affect regulation and emotional well-being: On the one hand, media induced affect can make individuals feel better immediately (e.g., in terms of regulating mood and arousal). On the other hand, affective responses to media content can serve to stimulate rewarding social and cognitive experiences that contribute to emotional well-being in more complex and sustainable ways (e.g., in that they foster a sense of meaning and social connectedness). The focus of this brief overview on affect regulation is not meant to deny the role of other motivations for entertainment use. Rather, this focus on affective factors serves to zoom in on one of the most important theoretical elements in entertainment research and to examine how this theoretical element can be linked to research on adult emotional development.

\section{Adult Emotional Development}

Adult emotional development is a relatively new research topic that has begun to change some of the bleak stereotypes about old age. According to a recent research overview of Charles 
and Carstensen (2010), older age is related to an overall increase in emotional well-being, marked by lower levels of negative affect, stable levels of positive affect, and increases in life satisfaction (with exceptions during the very last years of life). Two main lines of explanation have been proposed to account for this positive age trend in emotional well-being: biological decline of negative affect systems, and greater motivation and ability to regulate emotions.

Biological decline of negative affect systems. On the one hand, it has been proposed that a biological decline in emotion-sensitive brain areas and physiological systems may selectively diminish older adults' emotional responses to negative stimuli (Cacioppo, Berntson, Bechara, Tranel, \& Hawkley, 2011). Research on individuals' responses to film scenes (see overview of Kunzmann \& Grühn, 2005) has provided mixed support for this assumption, suggesting that the intensity of physiological responses to negative film stimuli decreases with age, whereas the intensity of subjective responses remains stable. However, when exposed to age-relevant themes such as the loss of loved ones, older adults showed comparable levels of physiological responses, and higher levels of subjective responses than young adults. Thus, older adults' lower physiological responsiveness of to negative stimuli does not seem to generalize to the themes most relevant to them, nor does it attenuate their subjective emotional responses to other negative stimuli.

The implications of these findings for entertainment research are somewhat ambiguous. Arousal regulation frameworks such as mood management (Zillmann, 1988) and sensation seeking (Zuckerman, 1979) assume that negative affect plays an important role in regulating aversive states of underarousal and boredom. Thus, a biological decline of negative affect systems should lead older adults to seek more intense entertainment stimuli to compensate for their low responsiveness_-which seems incompatible with the research evidence concerning older adults' low levels of sensation seeking, and their gentle content preferences (van der Goot et al, 2006; Zuckerman, 1979). On the other hand, according to Vorderer, Klimmt, and Ritterfeld (2004), entertainment is chiefly defined as a matter of subjective experience. That is, biological changes might leave entertainment experience unchanged as long as they do not change individuals' 
subjective responses to media stimuli. To follow up a possible influence of biological decline on subjective emotional responses to entertainment stimuli, a research question was formulated.

RQ1: Do older adults report lower levels of arousal and negative valence in response to film stimuli than young adults?

Motivation and ability to regulate emotions. An alternative set of explanations for older adults' increased emotional well-being is centered around the concept of emotion regulation. Several theories maintain that older adults are happier because they develop greater motivation and ability to regulate their emotions, for different reasons according to each theory. Some models are framed in terms of compensation (Heckhausen \& Schulz, 1995; Labouvie-Vief, 2003). For example, dynamic integration theory (Labouvie-Vief, 2003) assumes that regulation of negative affect serves to compensate for older adults' declining cognitive ability to integrate negative affect into complex and objective representations of the self and reality.

Other theories have drawn attention to individuals' active selection of emotional goals and priorities over the life span (Baltes \& Baltes, 1990; Carstensen et al., 2003). For example, socioemotional selectivity theory (Carstensen et al., 2003) holds that older adults develop a sense that lifetime is limited and precious, which leads them to focus more on achieving emotional balance and meaningfulness in the present as opposed to accepting negative experiences for the sake of long-term goals. In particular, this framework highlights the growing importance of close relationships as a source of meaning and emotional gratification in older adults.

In line with both compensation and selectivity models, a growing body of research indicates that older adults are better motivated and able to regulate emotions, especially in close relationships (see overview of Charles \& Carstensen, 2010). Apparently, older adults are most effective using antecedent-focused coping strategies such as avoidance and deescalation of conflict, and positive reappraisal. Moreover, they show a positivity bias in selective attention and memory. Evidence concerning response-focused coping including the regulation of arousal, feelings, and expressions is less conclusive, suggesting that older adults can regulate low levels of negative affect quite well but 
have greater difficulty when they experience higher levels of distress for longer periods of time. Overall, antecedent-focused emotion regulation seems to be a particular strength of older adults that helps them maintain high levels of emotional well-being despite the growing physical and cognitive challenges associated with aging.

Young adulthood, by contrast, has been described as a phase of exploration when individuals are particularly open to new and intense experiences, including negative affect. For example, Riediger, Schmiedek, Wagner, and Lindenberger (2009) found a heightened propensity among young adults to engage in contra-hedonic emotion regulation (i.e., behavior that brings about or intensifies negative affect). According to socioemotional selectivity theory (Carstensen et al., 2003), this openness to negativity is adaptive for young adults, because important information can be learned from negative experiences. However, once those lessons have been learned, it might become pointless for older adults to make the same negative experiences again.

Whether young adults' greater engagement with negative affect is a matter of goals and priorities (as assumed by socioemotional selectivity theory) or a matter of better cognitive functioning that allows them to maintain objectiveness and affective complexity in the face of negative experiences (as assumed by dynamic integration theory) is a subject of ongoing debate. Nevertheless, it seems safe to conclude that older adults are better motivated and able than young adults to use antecedentfocused coping to regulate emotions.

Consistent with antecedent-focused regulation of negative emotions, entertainment research has found that older adults tend to avoid violent and frightening content — though this pattern of findings is not as well supported as one might expect, because few samples included broad enough age ranges, according to a meta-analysis of Hoffner and Levine (2005). More rare are studies concerning older adults' interest in sad content. A recent study of Mares et al. (2008) based on socioemotional selectivity theory predicted and found that older adults were less interested in both sad and frightening content relative to young adults. Given that negative emotion words such as "scared" "sad," and "disturbing" that were used in this study may not count among the most typical 
descriptors of entertainment experience, it is interesting to note that a similar pattern of findings emerged when more typical descriptors were used. Bartsch (in press) found that when rating gratifications obtained from a movie they had recently seen, older adults reported less fear-related gratifications (phrased in terms of "thrill," "adrenaline," "tension," and "excitement"), and less sadness-related gratifications (phrased in terms of "poignancy," "moved to tears," "overwhelmed with emotion," and having "a good cry"). In sum, the theory and emerging empirical evidence lead to the following hypothesis about older adults' antecedent-focused regulation of negative emotions in entertainment use:

H1: Older adults are less motivated than young adults to seek entertainment gratifications related to negative affect (specifically, gratifications related to fear and sadness).

Theoretical conclusions about older adults' antecedent-focused regulation of positive emotions in entertainment use are less clear-cut. According to dynamic integration theory (Labouvie-Vief, 2003), older adults should prefer more light-weight positive entertainment experiences, because they are less capable of processing complex experiences that involve negativity. On the other hand, socioemotional selectivity theory (Carstensen et al., 2003; ErsnerHershfield et al., 2008) holds that older adults' emotion regulation is focused on a more complex type of positive experience that is characterized by social meaningfulness rather than hedonism, and that often involves feelings of mixed affective valence. A type of entertainment experience that corresponds with this need for social and emotional meaningfulness has been conceptualized by Oliver (2008) based on the distinction in ancient philosophy between hedonic and eudaimonic happiness (Aristotle, trans. 1931). Eudaimonic entertainment experience is characterized as contemplative and reflective, associated with warm, tender, and mixed feelings, and distinct from hedonic mood regulation (Oliver, 2008; Oliver \& Bartsch, 2010; Oliver \& Raney, 2011).

Recent studies seem to support the socioemotional selectivity view, suggesting a greater interest of older adults in heartwarming (Mares et al., 2008) and contemplative movies (Bartsch, in press), and a lesser interest of older adults in slapstick (Mares et al, 2008) and situation comedies 
(Mares \& Sun, 2010), relative to young adults. However, given the small number of findings, two alternative hypotheses based on dynamic integration theory $(\mathrm{H} 2)$, and socioemotional selectivity theory $(\mathrm{H} 3)$ were tested:

H2: Older adults are more motivated than young adults to seek entertainment gratifications related to positive affect (specifically, fun).

H3: Older adults are more motivated than young adults to seek entertainment gratifications related to social and emotional meaningfulness (specifically, contemplativeness).

Besides the four types of entertainment gratification addressed in the hypotheses (fear- and sadness-related gratifications, fun, and contemplativeness), the gratification factors reported by Bartsch (in press) include three additional dimensions: character engagement, social sharing of emotions, and vicarious release of emotions. Character engagement may be interpreted as a socially meaningful experience. Yet it was not included in H3, because Bleise (1986) found that a majority of older adults were dissatisfied with the role of media as a substitute for interpersonal contact, suggesting that parasocial interaction was less gratifying for them than actual social relationships. Social sharing of emotions was not included in $\mathrm{H} 3$ either, because on the one hand, it has been found that close relationships serve as an important source of meaning and emotional gratification for older adults, but on the other hand, their emotional investment becomes more selective, leading to a decrease in social network size (Carstensen et al., 2003). That is, older adults' motivation to share emotions with others likely depends on whom the experience is shared with. Given the lack of conclusive theoretical predictions, the following research question was included.

RQ2: Do young and older adults differ in their motivation to seek entertainment gratifications related to character engagement, social sharing, and vicarious release of emotions?

A further research question concerns the importance of different types of entertainment gratifications sought relative to each other within the two age groups. For example, the assumption that young adults are more interested in fear- and sadness-related gratifications than older adults, does not necessarily imply that sad and frightening experiences are the most salient gratification 
sought by this age group. Given the lack of available evidence, RQ 3 asks:

RQ3: How important are different types of emotional gratification relative to each other within young and older adults' entertainment gratifications sought?

Gratifications Sought vs. Gratifications Obtained.

The hypotheses and research questions discussed above are concerned with age differences in entertainment gratifications sought. A related issue that has not been addressed in the research literature so far pertains to the influence of age on gratifications obtained from actual exposure to entertainment media. It may seem self-evident that entertainment gratifications sought determine individuals' ability to actually experience and appreciate these gratifications when using entertainment media. On closer inspection however, this conclusion would be premature, given that gratifications sought and gratifications obtained are related in different ways to emotion regulation processes. Through the lens of Gross' (2002) model of emotion regulation, gratifications sought are related to a specific type of antecedent-focused emotion regulation, that is, situation selection (specifically, selective exposure to media content that accommodates individuals' affective needs). Once individuals are in an exposure situation, however, a number of additional processes may contribute to shaping emotional gratifications obtained: 1) emotional responsiveness, 2) additional aspects of antecedent-focused emotion regulation (i.e., selective attention and reappraisal), and 3) response-focused emotion regulation (i.e., physiological, behavioral, and experiential response modulation).

Given the divergent age trajectories of emotional responsiveness, antecedent-focused and response-focused emotion regulation discussed above, it seems less than trivial to disentangle the influence of these factors on entertainment gratifications obtained in a single study. However, an important first step is to examine which types of gratification factors contribute to young and older adults' positive experience of media stimuli, in case they are obtained. Does the experience of thrill or being moved to tears characterize a good movie for older adults as much as it does for young adults? Does the experience of contemplativeness contribute to young adults' sense of good 
entertainment as much as it does in older adults? These types of questions need to be answered before age differences in the level of gratifications obtained from specific stimuli can be examined in a meaningful way. For example, comparing the level of thrill experienced by young and older adults would be little informative if it remains unclear whether or not thrill contributes to older adults' sense that the entertainment experience was good and worthwhile.

To examine this issue, film scenes from different genres related to the emotional gratification factors addressed in Hypotheses 1 through 3 were included in the present research. Hypothesis 4 makes a general assumption about genre-typical gratification factors that should contribute to individuals' positive evaluation of film stimuli in the general sample, and Research Question 4 considers the possible moderating effect of age on this relationship.

H4: The experience of genre-typical gratifications obtained predicts individuals' positive evaluation of film stimuli (specifically, fun predicts comedy ratings, fear-related gratifications predict thriller ratings, sadness-related gratifications and contemplativeness predict drama ratings, and contemplativeness predicts documentary ratings).

RQ4: Does age have a moderating influence on the link between genre-typical gratifications obtained and positive ratings of film stimuli predicted in $\mathrm{H} 4$ ?

\section{Method}

Prior research into the life span development of entertainment experience has mainly focused on gratifications sought, either using ad hoc scales composed of emotion words and content characteristics (Mares et al., 2008), or genre items that have been interpreted as proxies for the types of gratifications sought (Mares \& Sun, 2010). Bartsch (in press) developed a set of scales to assess emotional entertainment gratifications in a more systematic manner, based on a factor analysis of individuals' agreement with statements derived from qualitative interviews. However, this study involved a confound of gratifications sought and gratifications obtained, given that emotional gratifications were assessed in the context of self-selected media use (e.g., video rental customers rated the movie they had rented). To provide an independent assessment of gratifications sought 
and obtained, participants of the present research were invited to the laboratory to view scenes from different film genres, and to rate emotional gratifications obtained after each scene. Gratifications sought were assessed before stimulus exposure, so as to be able to analyze them as distinct variables.

Participants and procedure. One hundred and sixty-two individuals participated in the study. Participants were recruited using advertisements in two local German newspapers and were paid a small fee for their participation. The sample was recruited from two age groups: young adults (ages 18-25) and older adults (age 50 and over), because these age groups have been linked to theoretically significant stages in emotional life span development (Carstensen et al., 2003). The sample included 82 young adults (42 male, 40 female, age $18-25, \mathrm{M}=21.60, \mathrm{SD}=2.66$ ), and 82 older adults (39 male, 43 female, age 50-80, $\mathrm{M}=63.10, \mathrm{SD}=6.85$ ). The study was conducted in a room equipped with a large screen, a projector, blinds, and speakers. Participants read and signed an informed consent form, and completed the first part of the questionnaire on emotional gratifications sought. Then they watched four film scenes and completed the second part of the questionnaire on gratifications obtained after each scene.

Stimuli. The film scenes used as stimuli were 7:30 to 10:00 minutes long and were taken from largely unknown movies, so as to avoid a confounding influence of prior knowledge on participants' experience of the scenes. Care was taken to select film scenes with topics of general age and gender comprehensive interest that would appeal to all age and gender groups alike. Scene 1 was a comedy scene about a likable loser who tries to win back his love. Scene 2 was a scene from a psycho-thriller about a psychopath who stalks a young woman. Scene 3 was from a drama about a mother who is forced to reveal a painful secret about her son who is the product of a rape. Scene 4 was a documentary scene about chicken farming. Though all scenes deal with issues of sexuality and/or violence on some level, no explicit sexual or violent portrayals were included (for more detailed descriptions of the scenes, see Appendix A).

Pretest. To ensure that the scenes were largely unknown and that they were representative 
of genre-typical movie experiences, a pretest was conducted. A convenience sample of 18 respondents from different age groups (7 male, 11 female, age 20-68, $M=41.89, S D=13.94$ ) viewed the scenes, indicated whether they had seen the movie before, and rated the scenes using the following items: "the scene was funny," "the scene was thrilling," "the scene was sad," and "the scene made me contemplative." The results showed that the film scenes were largely unknown and seemed to evoke the expected genre-typical experiences. Among the pretest sample no more than two participants had seen either scene. In terms of the rating criteria, no more than three participants disagreed that Scene 1 was funny, that Scene 2 was thrilling, that Scene 3 was sad and contemplative, or that Scene 3 was contemplative.

Measures. The first part of the questionnaire was completed by the participants before viewing the film scenes. Participants were asked to rate their agreement with 28 statements about emotional gratifications sought (Bartsch, in press). The first half-sentence was identical for all items: "I like to experience emotions when watching movies, because..." The second half-sentence was different for each item—for instance, fun: “...because it amuses me,” thrill: “...because I like the thrill of it," empathic sadness: “... because I like to have a good cry,” contemplativeness: “...because it makes me think about myself,” social sharing: “...because it inspires me to talk about the movie with others," character engagement: “...because I like to feel with characters,” and vicarious release: “...because it allows me to experience emotions that I avoid in everyday life.” Ratings were recorded on five-point scales ranging from 1 (strongly disagree) to 5 (strongly agree). Further, participants were asked to provide basic demographic information (age, gender, and education).

The second part of the questionnaire that was completed by the participants after each film scene asked them to indicate whether they had seen the movie before. Then participants were asked to indicate their agreement with the statement: "This film scene was really good." Subjective levels of arousal and negative valence were assessed using the SAM (Lang, 1980). Emotional gratifications obtained were assessed using the emotional gratification scales of Bartsch (in press). 
Due to methodological considerations, only five of the seven scales were included this time: fun, thrill, empathic sadness, contemplativeness, and character engagement, because the two remaining factors, social sharing of emotions and vicarious release of emotions, were unlikely to be experienced in a laboratory setting. All ratings except prior knowledge were recorded on five-point scales ranging from 1 (strongly disagree) to 5 (strongly agree).

\section{Results}

Exploratory and confirmatory factor analyses. To confirm the factor structure of the emotional gratification scales (Bartsch, in press) with regard to gratifications sought, exploratory and confirmatory factor analyses were conducted. First, a principle components factor analysis with varimax rotation was performed on the set of 28 scale items. Seven factors with eigenvalues greater than 1 emerged in this analysis that explained $66 \%$ of the variance. A subsequent run of confirmatory factor analysis using AMOS revealed an acceptable fit, $\left(\chi^{2 / \mathrm{df}}=1.48, \mathrm{CFI}=.90\right.$, RMSEA $=.05)$.

Reliability estimates. Reliability estimates using Cronbach's alpha were calculated for the scales employed. All scale alphas were in the acceptable range $(\alpha=.70$ to $\alpha=.90)$. Mean scores of the scale items were calculated and used in the subsequent analyses.

Stimulus checks. Two analyses were performed to ensure that the scenes were largely unknown among the sample and appealed to all age and gender groups alike. The stimulus check concerning prior knowledge revealed that four to fifteen percent of the participants had seen each scene before. To control for a confounding influence on other variables, prior knowledge was included as a control variable in the main analyses. A repeated measures analysis of variance of the four age and gender groups by ratings of the four film scenes revealed no significant interaction $\left(\right.$ Wilks' $\left.\Lambda=0.90, \mathrm{~F}(9,336)=1.67, \eta \mathrm{p}^{2}=0.03, \mathrm{p}>.05\right)$

Age differences in reported arousal and negative valence. The first part of the main analyses addressed a possible influence of biological decline on older adults' emotional 
responsiveness to the film stimuli (RQ1). Two repeated measures analyses of variance compared the two age groups by reported arousal and negative valence in response to the four film scenes. The first analysis revealed a significant influence of age on reported arousal (Wilks' $\Lambda=0.90, F(3,137)$ $=5.03, \eta p^{2}=0.10, p<.01$ ). Older adults reported more arousal in response to Scene 4 (young adults: $M=3.13, S D=1.29$; older adults: $M=3.68, S D=1.13, p<.01)$, no significant age differences emerged for the other three scenes. A second analysis of age groups by reported valence in response to the four scenes revealed no significant age effect (Wilks' $\Lambda=0.95, \mathrm{~F}(3,137)=2.60$, $\left.\eta p^{2}=0.05, p>.05\right)$. That is, no evidence of an age-related decline in emotional responsiveness to film stimuli was found on the level of subjective experience.

ANOVA of age groups by gratifications sought. The next analysis focused on differences in entertainment gratifications sought between age groups (H1-3, RQ2), and the relative importance of entertainment gratifications sought within age groups (RQ3). A mixed models analysis of variance of the two age groups by emotional gratifications sought was performed. Table 1 shows the results of this analysis (Wilks' $\Lambda=0.28, \mathrm{~F}(6,157)=68.28, \eta \mathrm{p}^{2}=0.72, \mathrm{p}<.001$ ). As expected, young adults were more interested than older adults in seeking fear- and sadness-related gratifications, and older adults were more interested than young adults in seeking contemplative entertainment experiences. That is, Hypothesis 1 was confirmed, Hypothesis 2 was not confirmed, and Hypothesis 3 was confirmed. No significant age differences concerning other types of gratifications sought emerged in this analysis.

Comparisons within age groups revealed that for young adults, fun and social sharing of emotions were the two most important gratifications sought. For older adults, three gratifications sought were equally most important: contemplativeness, social sharing, and fun. The least important gratification for young adults was vicarious release of emotions. For older adults, three gratifications were least important: fear- and sadness-related gratifications and vicarious release of emotions. Thus, young and older adults were similar concerning their interest in fun and social 
sharing of emotions, but older adults were more discriminating in their ratings of contemplativeness (which moved into the top group of gratifications sought) vs. fear- and sadness-related gratifications (which moved into the bottom group of gratification sought).

Emotional gratifications obtained as predictors of stimulus evaluations. The next set of analyses considered the role of emotional gratifications obtained in young and older adults' evaluation of the film stimuli. To confirm that in the general sample positive evaluations of the film scenes were driven by genre-typical gratifications obtained $(\mathrm{H} 4)$, a series of regression analyses was conducted. Age, gender, education and prior knowledge of the scenes were entered as control variables together with the five types of gratifications obtained from each scene. The results of this analysis as displayed in Table 2 showed that ratings of the scenes were predicted by genre-specific types of gratifications obtained as expected. Evaluations of the comedy scene were predicted by fun. Evaluations of the thriller scene were predicted by fear-related gratifications. Evaluations of the drama scene were predicted by sadness-related gratifications and contemplativeness.

Evaluations of the documentary scene were predicted by contemplativeness. Thus, Hypothesis 4 was confirmed. In addition, a positive influence of age on evaluations of Scenes 1, 2, and 3 emerged that was not evident in the comparison of age groups by scene ratings in the stimulus check. This pattern of results might reflect a positivity bias (Carstensen et al., 2003) in older adults' ratings of the scenes that was masked by the variance in genre-typical gratifications obtained.

Moderating effects of age. Finally, a set of moderated regression analyses examined the influence of age on the link between gratifications obtained and stimulus evaluations (RQ4). Hierarchical regression analyses were performed to predict positive evaluations of the film scenes. Gender, education and prior knowledge of the scenes were entered in the first step as control variables. In the second step, age was entered together with the respective type of gratification obtained that emerged as the critical predictor of positive ratings in the preceding analysis (e.g., fun for the comedy scene). The interaction term of age and the respective type of gratification obtained was entered in the third step. To facilitate the interpretation of moderation effects, mean-centered 
scores for gratifications obtained were used in this analysis. Regression weights of the control variables were similar to those in Table 2. Table 3 shows the results for the subsequent steps of the equation including age, gratifications obtained, and their interaction. Step 2 confirmed the expected influence of gratifications obtained on scene evaluations, as well as the positivity bias in older adults. However, step 3 revealed no interaction effect of age and gratifications obtained on evaluations of the scenes. Thus, the effect of fun, fear- and sadness-related gratifications, and contemplativeness on individuals' positive evaluations of the scenes was not dependent on a moderating influence of age, suggesting that these types of affective experiences were gratifying for young and older adults alike, in case they were obtained.

\section{Discussion}

This study set out to investigate the development of entertainment-related needs and viewing motivations over the life span, and came up with remarkable similarities as well as differences between young and older adults. Young adults were more interested than older adults in seeking gratifications related to fear and sadness such as thrilling and tear-jerking experiences, whereas older adults were more interested in seeking contemplative entertainment experiences. However, both age groups were similar in their seeking of other types of gratifications including fun, social sharing of emotions, emotional engagement with characters, and vicarious release of emotions. Moreover, young and older adults' ratings of film scenes from different genres suggest that they were equally appreciative of genre-typical gratifications obtained from the stimuli.

Older adults' lesser interest in fear- and sadness-related gratifications is compatible with assumptions about antecedent-focused emotion regulation as stated by different theories of adult development, including socioemotional selectivity theory (Carstensen et al., 2003) and dynamic integration theory (Labouvie-Vief, 2003). Both theories assume that older adults are motivated to a greater extent to avoid negative affect. Dynamic integration theory holds that a biological decline in cognitive abilities makes it more difficult for older adults to integrate negative experiences in a meaningful way. On the other hand, socioemotional selectivity theory assumes that the painful 
lessons that can be learned from negative experiences become less interesting for older adults, because they have already made these experiences earlier in life. To test these alternative interpretations, further research should include entertainment stimuli that deal with age-related challenges, so as to provide for negative experiences that are relevant enough to arouse older adults' interest and cognitive ambition. Moreover, measures of future time perspective (Carstensen \& Lang, 1996) and cognitive functioning (Labouvie-Vief, 2003) would be helpful to include in an attempt to distinguish between these alternative explanations.

Dynamic integration theory and socioemotional selectivity theory are also at variance concerning predictions about older adults' antecedent focused regulation of positive emotions. Dynamic integration theory holds that older adults become more hedonistic in their seeking of purely positive experiences, which should lead them to prefer more lightweight entertainment. The results do not support this assumption. Individuals' seeking of fun did not differ between age groups but was uniformly high. Further doubts about older adults' increasing focus on hedonism are raised by findings of other studies indicating that this age group was less interested in slapstick (Mares et al, 2008) and situation comedies (Mares \& Sun, 2010), and reported less fun obtained from a movie they had recently seen (Bartsch, in press). However, a potential confounding variable that was not controlled in these studies is character age, which is also related to age-specific themes (cf., Mares $\&$ Sun, 2010). In addition, comedies that feature hostile humor may not be perceived as unequivocally positive by older adults. Given that the mainstream choice of comedies available seems to be geared toward young adults, it is vital to control for character age and hostile humor when studying older adults' hedonistic entertainment gratifications.

Results on older adults' antecedent-focused regulation of positive emotions were more supportive of predictions derived from socioemotional selectivity theory (Carstensen et al., 2003). This framework assumes that older adults' seeking of emotional gratification becomes more focused on complex forms of positive experience that are ripe with social and emotional meaning. A related type of entertainment gratification has been conceptualized by Oliver and Raney (2011) in terms of 
eudaimonic entertainment, which is described as contemplative, reflective, and associated with warm, tender, and mixed feelings. The results of the present study suggest that older adults feel more attracted to this contemplative type of entertainment, consistent with prior research (Bartsch, in press; Mares et al., 2008). Besides fun and social sharing of emotions, contemplativeness emerged as one of the most important gratifications sought by older adults. Thus, it seems that the dominant focus of entertainment research on hedonism has tended to overlook a eudaimonic type of entertainment gratification that is no less important as a source of personal and emotional wellbeing, especially for older adults.

Perhaps even more important than the differences are the commonalities that emerged in this study. For example, young and older adults' interest in using entertainment as an opportunity to share emotions with others was uniformly high. The motivation to share emotions with others has clearly remained under-appreciated in the entertainment literature. It is interesting to note in this context that for both age groups emotional engagement with characters was less important than sharing emotions with real people. Thus, despite a long-standing theoretical fascination of entertainment research with parasocial relationships (Rubin \& Perse, 1987), and affective dispositions towards characters (Zillman \& Cantor, 1977), the sharing of emotions in personal relationships should not be overlooked as a motivation for entertainment use. Further research is needed to specify the types of affective experiences that young and older adults are interested in sharing (e.g., thrilling vs. contemplative experiences), and the types of relationships in which emotional entertainment experiences are shared.

Further similarities emerged concerning young and older adults' subjective emotional responses and their appreciation of gratifications obtained from the film stimuli. Subjective levels of arousal and negative valence were comparable, except that one of the scenes was rated more arousing by older adults. Consistent with prior research, no evidence of an age-related decline in emotional responsiveness was found on the level of subjective experience (cf., Kunzmann \& Grühn, 2005). Thus, it seems unlikely that differences in affective experience per se can explain the age- 
related changes in entertainment preferences.

Rather, the question seems to lie in older adults' ability to derive gratification from affective responses elicited by media stimuli. The present study took a first step toward exploring this issue by considering how different types of affective experiences including fear- and sadness-related gratifications, fun, and contemplativeness contribute to individuals' positive evaluation of film scenes as a function of age. The findings suggest that, on a general level, young and older adults did not differ in their ability to derive gratification from such experiences. Those who reported these gratifications rated the film scenes more favorably, independent of age. Thus, individuals' general ability to derive gratification from affective experiences does not seem to provide a sufficient explanation for age differences in entertainment preferences either.

\section{Limitations and Outlook}

An important next question that has not been addressed in this study concerns the ease with which emotional gratifications can be obtained from typical entertainment genres as a function of age. In the interest of studying multiple types of gratification factors at a time, the present study included a heterogeneous set of film stimuli from different genres. This procedure made it difficult to compare young and older adults' absolute levels of gratifications obtained from the film scenes in a meaningful way, because the level of gratifications obtained from a single stimulus can not be generalized to the genre as a whole (as opposed to correlations with positive ratings that can be observed at different levels of gratifications obtained). To compare young and older adults' absolute levels of gratifications obtained from specific genres, further research using a broader and more representative array of entertainment stimuli is needed.

As noted in the theory section, a more in-depth examination of affect regulation processes during media exposure might help elucidate and predict age differences in the level of entertainment gratifications obtained from specific stimuli. For instance, older adults might find it easier to derive gratification from media content that accommodates their preference for antecedent-focused coping strategies such as positive reappraisal (e.g., content that fosters understanding and forgiveness)— 
whereas they might experience greater difficulty using response focused coping to deal with intense and apparently meaningless forms of emotional stimulation (e.g., gratuitous violence). The limitations of this study did not allow for a systematic variation of content characteristics that may constrain the effectiveness of emotion regulation strategies during media exposure, leaving this question unanswered.

Another important limitation of the present study lies in the non-representative and crosssectional nature of the sample. To disentangle developmental changes from cohort differences, longitudinal research is needed. For example, without longitudinal data it cannot be ruled out that older adults' greater interest in contemplative movie experiences and their lesser interest in thrilling and tear-jerking experiences may reflect preferences for different types of movies that were popular during their youth rather than developmental changes. Thus, the interaction between the evolving entertainment landscape and individuals' evolving needs and expectations concerning entertainment needs to be taken into account.

The results are also limited with regard to the specific type of entertainment medium and the cultural background of the participants. The available evidence concerning age differences in entertainment gratifications sought suggest a similar pattern of results for movie and TV audiences (Bartsch, in press; Mares et al., 2008; Mares \& Sun, 2010), and the present findings add to the generalizability of results across US and German samples. However, more research is needed including not only audiovisual media but also print and interactive media, as well as participants from more diverse cultural backgrounds.

Another limitation concerns the conceptual background of the self-report measures used to assess entertainment gratifications. The factor structure of this recently developed measure has been validated in a small number of studies, and has been linked to theoretical concepts in entertainment research (Bartsch, in press). Yet, the empirical distinctiveness of dimensions in individuals' selfreport does not necessarily speak to the conceptual distinctiveness of underlying gratification factors. For example, fun and thrill motivations might reflect different aspects of mood 
management (i.e., the regulation of affective valence vs. arousal). Likewise, empathic sadness and contemplativeness might reflect different facets of eudaimonic gratification, given that both are often associated with the experience of tragic drama. The divergent age trajectories of these two pairs of factors (fun vs. thrill, and sadness vs. contemplativeness) in terms of gratifications sought, and their different roles in predicting film evaluations, lend preliminary support to the usefulness of treating them as distinct variables (for a related argument concerning the distinction between sadness and eudaimonic motivations, see Oliver, 2008; Oliver \& Raney, 2011). Nevertheless, further research is necessary to confirm the conceptual distinctiveness of these factors and to clarify their relationship with research on gratification factors that motivate media use in general (Conway \& Rubin, 1991; Rubin \& Perse, 1987). In particular, the link between older adults' heightened interest in contemplative experiences and their preference for informational content merits further attention (cf., Mares and Sun, 2010). In this context, intrinsic motivations such as the seeking of contemplativeness (as a eudaimonic gratification) need to be distinguished from instrumental motives such as the seeking of useful information.

With all the limitations in mind, the present findings contribute to an emerging understanding of the changing needs and viewing motivations that account for individuals' changing entertainment preferences over the life span. While entertainment research has long puzzled over the paradoxical appeal of frightening and tear-jerking experiences that are more typical of young adults' entertainment diets, research has tended to overlook social and cognitive gratifications that are most appealing for older adults. More in-depth consideration of entertainment gratifications such as contemplativeness and social sharing of emotions may not only further our understanding of the appeals and functions of entertainment for older adults but may also inform the study of viewing motivations that have remained underestimated in young adults and adolescents. Studying older adult's entertainment use may teach us to use entertainment wisely, given the particular experience of this age group in sustainable affect regulation and emotional well-being. 


\section{References}

Aristotle. (1931). Nicomachean ethics (W. D. Ross, Trans.). London: Oxford University Press.

Baltes, P. B., \& Baltes, M. M. (1990). Psychological perspectives on successful aging: The model of selective optimization with compensation. In P. B. Baltes \& M. M. Baltes (Eds.), Successful aging: Perspectives from the behavioral sciences (pp. 1-34). Cambridge, MA: Cambridge University Press.

Bartsch, A. (in press). Emotional Gratification in Entertainment Experience. Why Viewers of Movies and TV Series Find it Rewarding to Experience Emotions. Media Psychology.

Bartsch, A., Vorderer, P., Mangold, R., \& Viehoff, R. (2008). Appraisal of Emotions in Media Use: Toward a Process Model of Meta-Emotion and Emotion Regulation. Media Psychology, 11, 7-27. doi:10.1080/15213260701813447

Bleise, N. W. (1986). Media in the rocking chair: Media uses and functions among the elderly. In G. Gumpert \& R. Cathcart (Eds.), Intermedia: Interpersonal communication in a media world (pp. 573-582). New York: Oxford University Press.

Cacioppo, J. T., Berntson, G. G., Bechara, A., Tranel, D., \& Hawkley, L. C. (2011). Could an aging brain contribute to subjective well being?: The value added by a social neuroscience perspective. In A. Tadorov, S. T. Fiske, \& D. Prentice (Eds.), Social Neuroscience: Toward Understanding the Underpinnings of the Social Mind (pp. 249-262). New York: Oxford University Press.

Carstensen, L., Fung, H., \& Charles, S. (2003). Socioemotional selectivity theory and the regulation of emotion in the second half of life. Motivation and Emotion, 27, 103-123. doi:10.1023/A:1024569803230

Carstensen, L. L., \& Lang, F. R. (1996). Future Time Perspective Scale. Unpublished manuscript. Stanford University.

Charles, S. T., \& Carstensen, L. L. (2010). Social and Emotional Aging. Annual Review of Psychology, 61, 383-409. doi:10.1146/annurev.psych.093008.100448 
Conway, J. C., \& Rubin, A. M. (1991). Psychological Predictors of Television Viewing Motivation. Communication Research, 18(4), 443 -463. doi:10.1177/009365091018004001

Csikszentmihalyi, M. (1990). Flow: The psychology of optimal experience. New York: Harper Collins.

Ersner-Hershfield, H., Mikels, J. A., Sullivan, S. J., \& Carstensen, L. L. (2008). Poignancy: Mixed emotional experience in the face of meaningful endings. Journal of Personality and Social Psychology, 94, 158-167. doi:10.1037/0022-3514.94.1.158

Fischoff, S., Antonio, J., \& Lewis, D. (1998). Favorite films and film genres as a function of race, age and gender. Journal of Media Psychology, 3(1).

Gross, J. J. (2002). Emotion regulation: Affective, cognitive, and social consequences. Psychophysiology, 39, 281-291. doi: 10.1017.S0048577201393198

Heckhausen, J., \& Schulz, R. (1995). A life-span theory of control. Psychological Review, 102, 284304.

Hoffner, C. A., \& Levine, K. J. (2005). Enjoyment of Mediated Fright and Violence: A MetaAnalysis. Media Psychology, 7(2), 207-237.doi:10.1207/S1532785XMEP0702_5

Kunzmann, U., \& Grühn, D. (2005). Age differences in emotional reactivity: the sample case of sadness. Psychology and Aging, 20, 47-59. doi:10.1037/0882-7974.20.1.47

Labouvie-Vief, G. (2003). Dynamic integration: affect, cognition, and the self in adulthood. Current Directions in Psychological Science, 12, 201-206. doi:10.1046/j.0963-7214.2003.01262.x

Lang, P. J. (1980). Behavioral treatment and bio-behavioral assessment: computer applications. In J. B. Sidowski, J. H. Johnson, \& T. A. Williams (Eds.), Technology in mental health care delivery systems (pp. 119-137). Norwood, NJ: Ablex.

Mares, M. L., \& Cantor, J. (1992). Elderly viewers' responses to televised portrayals of old age: Empathy and mood management versus social comparison. Communication Research, 19, 459-478. doi:10.1177/009365092019004004

Mares, M. L., Oliver, M. B., \& Cantor, J. (2008). Age differences in adults' emotional motivations 
for exposure to films. Media Psychology, 11, 488-511. doi:10.1080/15213260802492026

Mares, M., \& Sun, Y. (2010). The Multiple Meanings of Age for Television Content Preferences. Human Communication Research, 36, 372-396. doi:10.1111/j.1468-2958.2010.01380.x

Mundorf, N., \& Brownell, W. (1990). Media preferences of older and younger adults. The Gerontologist, 30, 685-691. doi:10.1093/geront/30.5.685

Oliver, M. B. (1993). Exploring the paradox of the enjoyment of sad films. Human Communication Research, 19, 315-342. doi:10.1111/j.1468-2958.1993.tb00304.x

Oliver, M. B. (2008). Tender affective states as predictors of entertainment preference. Journal of Communication, 58, 40-61. doi:10.1111/j.1460-2466.2007.00373.x

Oliver, M. B., \& Bartsch, A. (2010). Appreciation as Audience Response: Exploring Entertainment Gratifications Beyond Hedonism. Human Communication Research, 36, 53-81. doi:10.1111/j.1468-2958.2009.01368.x

Oliver, M. B., \& Raney, A. A. (2011). Entertainment as pleasurable and meaningful: Differentiating hedonic and eudaimonic motivations for entertainment consumption. Journal of Communication, 64, 984-1004.

Riediger, M., Schmiedek, F., Wagner, G. G., \& Lindenberger, U. (2009). Seeking pleasure and seeking pain: Differences in pro- and contra-hedonic motivation from adolescence to old age. Psychological Science, 20, 1529-1535.

Rubin, A. M., \& Perse, E. M. (1987). Audience activity and soap opera involvement: A uses and effects investigation. Human Communication Research, 14, 246-268. doi:10.1111/j.14682958.1987.tb00129.x

Ryan, R. M., \& Deci, E. L. (2000). Self-determination theory and the facilitation of intrinsic motivation, social development, and well-being. American Psychologist, 55, 68-78. doi:10.1037/0003-066X.55.1.68

Sherry, J. L. (2004). Flow and Media Enjoyment. Communication Theory, 14(4), 328-347. doi:10.1111/j.1468-2885.2004.tb00318.x 
Tamborini, R., Bowman, N. D., Eden, A., Grizzard, M., \& Organ, A. (2010). Defining Media Enjoyment as the Satisfaction of Intrinsic Needs. Journal of Communication, 60, 758-777. doi:10.1111/j.1460-2466.2010.01513.x

van der Goot, M., Beentjes, J. W. J., \& van Selm, M. (2006). Older adults' television viewing from a life-span perspective: Past research and future challenges. In C. S. Beck (Ed.), Communication Yearbook, 30 (pp. 431-469). Mahwah, NJ: Lawrence Erlbaum.

Vorderer, P., Klimmt, C., \& Ritterfeld, U. (2004). Enjoyment: At the Heart of Media Entertainment. Communication Theory, 14, 388-408. doi:10.1111/j.1468-2885.2004.tb00321.x

Vorderer, P., Steen, F., \& Chan, E. (2006). Motivation. In J. Bryant \& P. Vorderer (Eds.), Psychology of entertainment (pp. 3-17). Mahwah, NJ: Lawrence Erlbaum Associates.

Zillmann, D. (1988). Mood management through communication choices. American Behavioral Scientist, 31, 327-340. doi:10.1177/000276488031003005

Zillmann, D. (1996). The psychology of suspense in dramatic exposition. In P. Vorderer, H. J. Wulff \& M. Friedrichsen (Eds.), Suspense: Conceptualizations, theoretical analyses, and empirical explorations (pp. 199-231). Mahwah, NJ: Lawrence Erlbaum Associates.

Zillman, D., \& Cantor, J. R. (1977). Affective responses to the emotions of a protagonist. Journal of Experimental Social Psychology, 13, 155-165. doi:16/S0022-1031(77)80008-5

Zuckerman, M. (1979). Sensation Seeking: Beyond the optimal level of arousal. New York: Wiley. 
Table 1

Mixed Models ANOVA of Emotional Gratifications Sought Within and Between Age Groups

Age Group

\begin{tabular}{llc}
\hline Emotional Gratifications Sought & $\begin{array}{l}\text { Young Adults } \\
(18-25)\end{array}$ & $\begin{array}{l}\text { Older Adults } \\
(50+)\end{array}$ \\
\hline Fun & $3.80 \mathrm{~A} \mathrm{a}$ & $3.83 \mathrm{~A} \mathrm{a}$ \\
Fear-Related & $3.34 \mathrm{~A} \mathrm{bc}$ & $2.75 \mathrm{~B} \mathrm{c}$ \\
Sadness-Related & $2.96 \mathrm{~A} \mathrm{~d}$ & $2.63 \mathrm{~B} \mathrm{c}$ \\
Contemplative & $3.49 \mathrm{~B} \mathrm{~b}$ & $3.84 \mathrm{~A} \mathrm{a}$ \\
Character Engagement & $3.17 \mathrm{~A} \mathrm{~cd}$ & $3.11_{\mathrm{A} \mathrm{b}}$ \\
Social Sharing & $3.81 \mathrm{~A} \mathrm{a}$ & $3.84 \mathrm{~A} \mathrm{a}$ \\
Vicarious Release & $2.44_{\mathrm{A} \mathrm{e}}$ & $2.75 \mathrm{~A} \mathrm{c}$ \\
\hline
\end{tabular}

Note: Within rows, means with no upper case subscripts in common differ at $p<.05$. Within columns, values with no lower case subscripts in common differ at $p<.05$ using sequential Bonferroni procedures. 
Table 2

Emotional Gratifications Obtained as Predictors of Positive Evaluations of Film Scenes

\begin{tabular}{lllll}
\hline & \multicolumn{3}{c}{ Film Scene } \\
\cline { 2 - 5 } & 1 & 2 & 3 & 4 \\
& Comedy & Thriller & Drama & Documentary \\
\hline Control Variables & & & & \\
Prior Knowledge & .00 & -.04 & -.11 & -.04 \\
Age & $.18^{* *}$ & $.18^{*}$ & $.19^{*}$ & -.03 \\
Gender (male) & .04 & .00 & .14 & .15 \\
Education & -.01 & .14 & -.08 & $.25^{* *}$ \\
\hline Gratifications Obtained & & & .07 & .03 \\
Fun & $.67^{* *}$ & -.07 & -.09 & .06 \\
Fear-Related & .17 & $.33^{* *}$ & .03 & .02 \\
Sadness-Related & -.05 & -.03 & $.25^{* *}$ & $.25^{* *}$ \\
Contemplative & -.02 & .11 & $.25^{* *}$ & .12 \\
Character Engagement & .10 & .16 & .08 & .24 \\
\hline R & .64 & .20 & .24 & \\
F Change & $27.15^{* *}$ & $3.98^{* *}$ & $4.99^{* *}$ & \\
\hline
\end{tabular}

$* p<.05 . * * p<.01$.

Note: Scores are standardized regression weights. 
Table 3

Moderated Regression Analyses Concerning the Influence of Age on the Relationship of Gratifications Obtained with Scene Evaluations

Film Scene

(Type of Gratification Considered as Predictor of Evaluations)

\begin{tabular}{lllll}
\hline Comedy & Thriller & Drama & Drama & $\begin{array}{l}\text { Documentary } \\
\text { (Fun) }\end{array}$ \\
& (Fear- & (Sadness- & (Contem- & (Contem- \\
& Related) & Related $)$ & plative $)$ & plative $)$
\end{tabular}

Step 2

Age

$.15^{*}$

$.22 *$

$.22 * *$

$.14^{*}$

$-.03$

Gratification Obtained

$.77 * *$

$.40 * *$

$.33^{* *}$

$.37 * *$

$.30 * *$

Step 3

Age $x$

Gratification Obtained $-.09$

.06

$-.03$

.03

.21

$* p<.05 . * * p<.01$.

Notes: Scores are standardized regression weights.

The regression regression weights for the control variables in step 1 (prior knowledge, gender and education) were similar to the scores displayed in Table 2 and are, therefore, not reported. 
Appendix A: Description of the Film Stimuli

Scene 1 (comedy, runtime: 10:00 min.): Scene 1 is from the comedy 666 - In Bed with the Devil (Germany, 2002). Frank, a likable loser, makes a pact with the devil to win back his love. The devil has the ability to transform into German sports and movie stars (acted by the real stars), and uses this ability to impress Frank's ex-girlfriend and to make her jealous. Finally, the girlfriend comes back and apologizes. After midnight, the bell rings, and the girlfriend comes back and apologizes a second time. Frank suddenly realizes that the first "girl friend" he spent the night with was the devil.

Scene 2 (suspense, runtime: 7:30 min.): Scene 2 is from the psycho-thriller The Free Will (Germany, 2006). A formerly convicted rapist who has recently been released from prison watches an unknown woman who works at a department store. After closing time, he stalks her, follows her at home, and breaks into her apartment. He watches her sleep and cautiously pulls her blanket off without waking her up. After staring at her for a while and nearly touching her, he decides otherwise and steals away.

Scene 3 (drama, runtime 9:00 min.): Scene 3 is from the drama North Country (USA, 2005). Josey Aimes sues her employer, a mining company, because the company refuses to act against sexual harassment of the female workers. During the lawsuit she is forced by the counter-party's attorney to reveal a painful secret: As a teenager she has been raped by her high-school teacher. Her son with whom she has a difficult relationship runs away from home after he learns the truth. At the end of the scene mother and son reconcile.

Scene 4 (documentary, runtime 8:50 min.): Scene 4 is from the documentary We Feed the Wold (Austria, 2005). The scene is about factory chicken farming. Austrian chicken farmers are interviewed about their work, and the life-cycle of chicken is shown from the breeding chamber through the mast facility to the arrival of the chicken at the slaughterhouse. The slaughtering itself is not part of the scene. 